\title{
POSTCOLONIAL RESPONSES
}

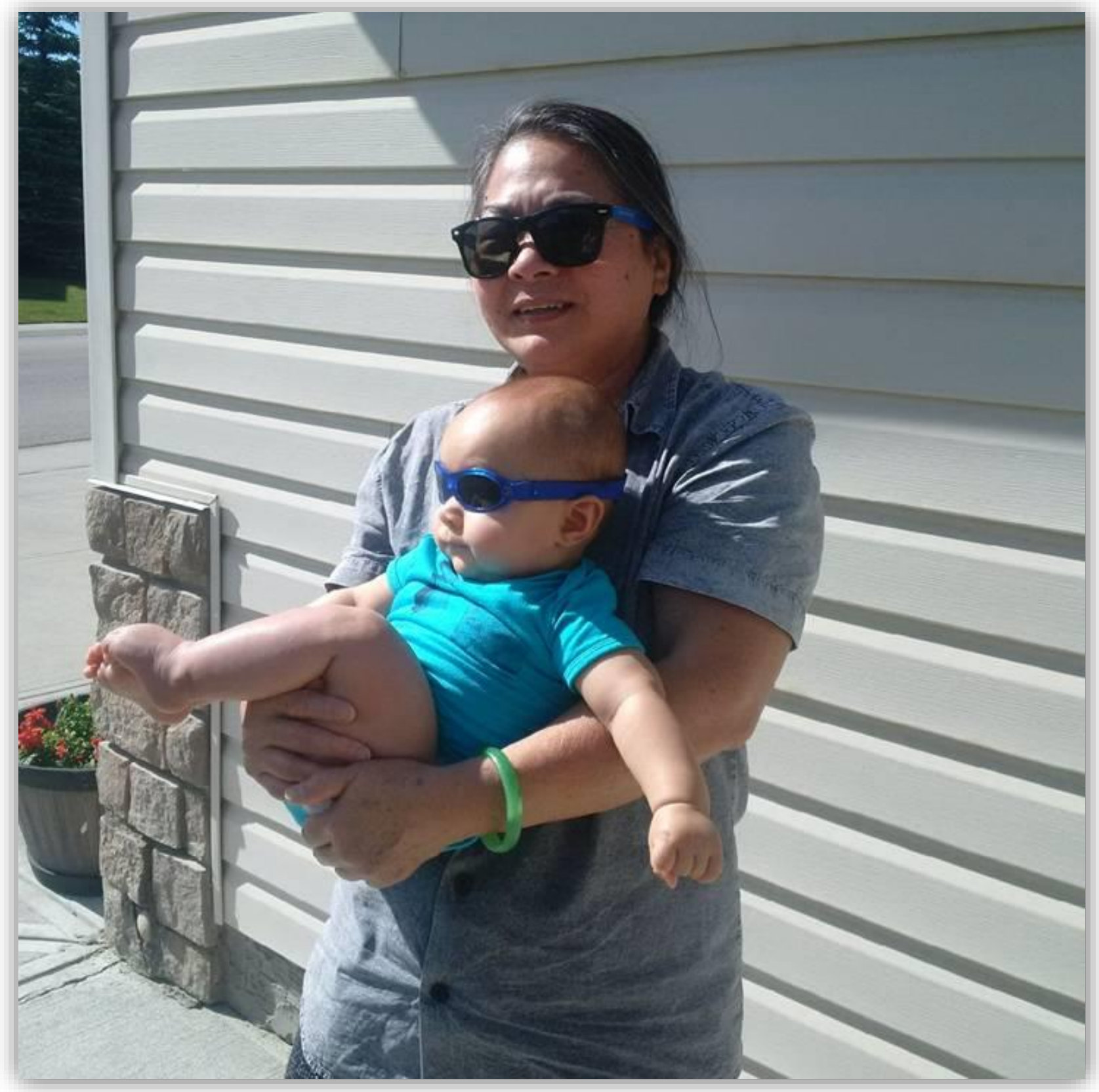

“...Life is just for Living...” (Ernie Smith, popular reggae composer, and performing artist)

Photograph: Lincoln Isbister with his grandma, Dr. Donna Chin Fatt, High River, Southern Alberta

(Permission granted by Chin Fatt Family to include the photograph in the CPI summer 2015, Special Issue)

Cultural and Pedagogical Inquiry, 2015, 7(1), p. 117

ISSN 1916-3460 () 2015 University of Alberta

http://ejournals.library.ualberta.ca/index.php/cpi/index 